\title{
IMPROVED RELIABILITY OF IMPEDANCE CARDIOGRAPHY BY NEW SIGNAL PROCESSING TECHNIQUES
}

\author{
S.P. Reddy, L.Y. Shyu, B.E. Hurwitz, J.H. Nagel, N. Schneiderman \\ Behavioral Medicine Research Center \\ Departments of Biomedical Engineering, Psychology, and Medicine \\ University of Miami, Coral Gables, Florida
}

\begin{abstract}
This study used the impedance cardiogram (ICG), the phonocardiogram (PCG) and the electrocardiogram (ECG) to determine stroke volume and systolic time intervals. Comparisons between a fully automated PC-AT signal processing system and a computer-assisted visual detection processing system revealed comparable means, standard errors, correlations (Spearman $r$ ) and reliability (Chronbach's $\alpha$ ) coefficients on all relevant parameters. Other analyses confirmed the utility of using $Q$ onset to mark the beginning of ventricular systole, the B point of the ICG to denote the aortic opening and end diastole as the reference for determining the amplitude of $\mathrm{dZ} / \mathrm{dt}_{\max }$.
\end{abstract}

\section{INTRODUCTION}

Common signal processing techniques have used spectral filters along with simple threshold detection algorithms for segmentation and measurement of cardiac signals to obtain the relevant parameters: interbeat interval (IBD), pre-ejection period (PEP), left ventricular ejection time (LVET), electromechanical systole (QS2), electrical systole (QT), maximum systolic impedance change ( $\left.\mathrm{dZ} / \mathrm{dt}_{\max }\right)$, stroke volume (SV) and cardiac output $(\mathrm{CO})$. By using recent advances in filter technique and improved algorithms as described in the previous paper by Shyu and associates, we attempted to develop an entirely computerized detection system that could approximate the results of computer-assisted visual signal analysis. Therefore, in the present study algorithms were developed to determine all relevant ECG, PCG, and ICG events using a fully computerized PC-AT system. Comparisons were then made between this system and a partially computerized visual inspection system in which computer graphics permitted the operator to place cursors on the displayed signals and automatically obtain computer derived calculations of the cardiac parameters.

In addition to testing the fully computerized signal-processing system, the present study evaluated the use of several alternative algorithms. The beginning of electrical ventricular systole, for example, is indicated in the ECG by the onset of the Q-wave (1, Figure 1). Due to difficulty in determination of slow wave onsets, conventional techniques are sometimes inadequate for precisely defining this event. For this reason some investigators have chosen to use the so called $Q$ minimum or sharp upstroke of the $R$ wave $\left(Q_{u}\right.$, Figure 1$)$. The present study assessed the extent of the differences between $Q$ onset and $Q$ minimum methods.

The aortic opening has been detected by three different methods: (1) the second zero crossing in the first heart sound
(S1) detected using the PCG (2, Figure 1); (2) the zero crossing in the $\mathrm{dZ} / \mathrm{dt}$ waveform using the ICG (3, Figure 1); and (3) the B point of the ICG (B, Figure 1). The signal quality of the PCG is often unsatisfactory during speech or exercise. The zero crossing in the $\mathrm{dZ} / \mathrm{dt}$ waveform may vary with respect to the zero line as a function of respiration (5, Figure 1). In order to assess the effects of these differences the present study compared $\mathrm{dZ} / \mathrm{dt}_{\max }$ using either the zero line or end diastole (ED, Figure 1). Finally, the present study compared the use of the B point with the other methods of detecting the aortic opening to determine whether systematic differences among measures exist.

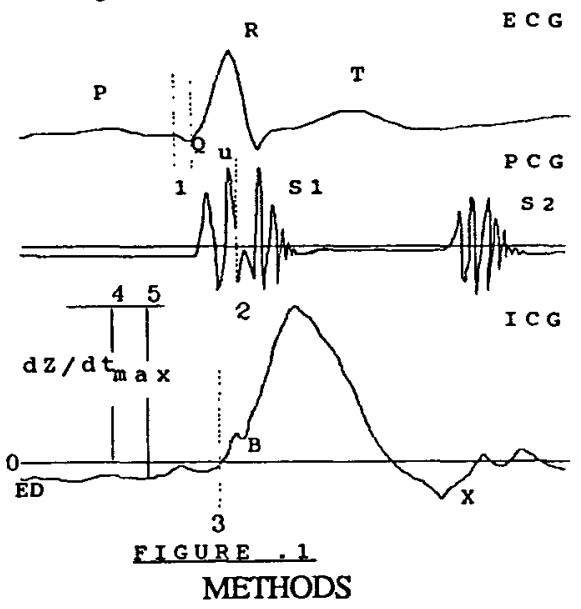

Subjects were nine males and one female. The ECG, PCG, and ICG were stored digitally using a sampling rate of $1 \mathrm{kHz}$. Seated subjects were instructed to inhale and exhale as fully as possible during paced breathing. Breathing was paced by an audio recording such that inspiration and expiration intervals were each five seconds in duration. The paced respiration task lasted for two minutes. Data were obtained during the last 30 seconds.

\section{RESULTS and DISCUSSION}

The results obtained by computer-assisted visual analysis and by fully automated computerized analysis are shown in Table 1 . It can be seen that the means and standard errors obtained by the two systems were nearly identical. In addition, the correlation (Spearman $r$ ) and reliability (Chronbach's $\alpha$ ) coefficients were very high. It thus appears that the fully automated system was at least as reliable as the computer-assisted visual editing system under the conditions tested. 
Table 1. Visual Processing (V) vs Automated Processing(C)

\begin{tabular}{|c|c|c|c|c|}
\hline Parameter & & Mean $\pm S E$ & $\begin{array}{l}\text { Zorrelation } \\
\text {-oefficient } r\end{array}$ & Reliability $\alpha$ \\
\hline $\begin{array}{l}\text { IBI } \\
\text { (msec) }\end{array}$ & (V) & $\begin{array}{l}806.84 \pm 46.71 \\
807.03 \pm 46.61\end{array}$ & 1.000 & 1.000 \\
\hline $\begin{array}{l}\text { PEP } \\
\text { (msec) }\end{array}$ & $\begin{array}{l}\text { (V) } \\
\text { (C) }\end{array}$ & $\begin{array}{ll}108.59 & 3.78 \\
106.23_{ \pm} & 3.95\end{array}$ & .88 & .92 \\
\hline $\begin{array}{l}\text { LVET } \\
\text { (msec) }\end{array}$ & (V) & $\begin{array}{l}265.06 \pm 9.39 \\
263.90 \pm 9.61\end{array}$ & .97 & .99 \\
\hline $\begin{array}{l}\text { QS2 } \\
\text { (msec) }\end{array}$ & (V) & $\begin{array}{l}371.63 \pm 9.41 \\
370.13_{ \pm} 9.35\end{array}$ & .97 & .98 \\
\hline $\begin{array}{l}\text { QT } \\
\text { (msec) }\end{array}$ & (V) & $\begin{array}{l}361.17 \pm 15.28 \\
357.30 \pm 15.53\end{array}$ & .97 & .98 \\
\hline $\begin{array}{l}\mathrm{d} / \mathrm{dt} \\
\text { (ohms/sec) }\end{array}$ & (V) & $\begin{array}{ll}2.18 \pm & .16 \\
2.18 \pm & .17\end{array}$ & .997 & .999 \\
\hline $\begin{array}{l}\text { SV } \\
\text { (ml) }\end{array}$ & (C) & $\begin{array}{ll}71.34 \pm & 6.68 \\
71.22 \pm & 7.64\end{array}$ & .997 & .998 \\
\hline $\begin{array}{l}C O \\
\text { (liters/min) }\end{array}$ & (V) & $\begin{array}{l}5.42+0.62 \\
5.42+0.60\end{array}$ & .997 & .998 \\
\hline
\end{tabular}

Table 2 compares the computer analysis of $Q$ onset ( 1 , Figure 1) with the upstroke ( $Q_{u}$, Figure 1) of the $R$ wave. It can be seen that the use of $Q_{u}$ leads to the consistent underestimation of PEP, QS2, and QT, although the correlation and reliability coefficients for QS2 and QT remained high. Therefore, to the extent that $Q$ onset can be reliably detected, it appears to be a better reference point for the onset of electrical ventricular systole.

Table 2. Yariations in Ventricular Systole Using O-onses (O) ys Q-minimum(Om)

\begin{tabular}{|c|c|c|c|c|}
\hline \multicolumn{2}{|c|}{ Parameter } & \multirow{2}{*}{$\begin{array}{c}\text { Mean } \pm S E \\
\begin{array}{r}106.23 \pm \\
94.15 \pm 3.70\end{array}\end{array}$} & \multirow{2}{*}{$\begin{array}{c}\begin{array}{l}\text { Correlation } \\
\text { Coefficient r }\end{array} \\
.69\end{array}$} & \multirow{2}{*}{$\frac{\text { Reliability } \alpha}{.80}$} \\
\hline $\begin{array}{l}\text { PEP } \\
\text { (msec) }\end{array}$ & $\begin{array}{l}(Q 0) \\
(Q m)\end{array}$ & & & \\
\hline $\begin{array}{l}\mathrm{QS} 2 \\
\text { (msec) }\end{array}$ & $\begin{array}{l}(\mathrm{Q}) \\
(\mathrm{Qm})\end{array}$ & $\begin{array}{l}370.13 \pm 9.35 \\
358.13 \pm 9.72\end{array}$ & .93 & .96 \\
\hline $\begin{array}{l}\mathrm{QT} \\
\text { (msec) }\end{array}$ & $\begin{array}{l}(\mathrm{Qo}) \\
(\mathrm{Qm})\end{array}$ & $\begin{array}{l}357.30 \pm 15.53 \\
345.91 \pm 14.89\end{array}$ & .99 & .99 \\
\hline
\end{tabular}

Table 3 compares the use of the B point of the ICG with the second zero crossing of the PCG and with the zero crossing of the $\mathrm{dZ} / \mathrm{dt}$ waveform in detecting the aortic opening. It can be seen in comparisons between the use of the B point and the second zero crossing of the PCG that the mean values for PEP and LVET are comparable. However, the variance using the PCG method is higher than the B point method for PEP. This difference in variance appears to be reflected in the low reliability coefficient observed for PEP. To the extent that the PCG method is limited because it cannot be used during speaking or vigorous exercise, use of the B point would appear to be more advantageous.

In comparing the use of the B point with the zero crossing of the dZ/dt waveform for detecting the aortic opening, it can be seen that the variance is again smaller when the $B$ point is used. It can also be seen that relative to either the $B$ point or the zero crossing of the PCG, the zero crossing of the $\mathrm{dZ} / \mathrm{dt}$ waveform tends to underestimate PEP and to overestimate LVET. It would therefore appear that in terms of determining systolic time intervals, use of the B point appears to be preferable to using either the second zero crossing of the PCG or the zero crossing of the dZ/dt waveform. Moreover, the overestimation of LVET is likely to inflate systematically the calculation of stroke volume.

Table 3. Variations of Opening Time and dz/di $\max$

\begin{tabular}{|c|c|c|c|c|}
\hline & Parameter & Mean $_{ \pm} \mathrm{SE}$ & $\begin{array}{l}\text { Correlation } \\
\text { Coefficient r }\end{array}$ & Reliability $\alpha$ \\
\hline $\begin{array}{c}\text { B-Point (B) } \\
\text { vs }\end{array}$ & $\begin{array}{l}\text { (B) PEP } \\
\text { (S1) (msec) }\end{array}$ & $\begin{array}{ll}106.23 \pm & 3.95 \\
107.63_{ \pm} & 6.07\end{array}$ & .55 & .64 \\
\hline SI Opening (S1) & $\begin{array}{l}\text { (B) LVET } \\
\text { (S1) (msec) }\end{array}$ & $\begin{array}{l}263.90 \pm 9.61 \\
262.30 \pm 10.10\end{array}$ & .85 & .92 \\
\hline$\underset{\text { vs }}{\text { B-Point (B) }}$ & $\begin{array}{l}\text { (B) PEP } \\
\text { (Bo)(msec) }\end{array}$ & $\begin{array}{ll}105.53_{ \pm} & 3.65 \\
101.76_{ \pm} & 7.76\end{array}$ & .55 & .57 \\
\hline \multirow[t]{2}{*}{$\begin{array}{l}\text { B-Zero Crossing } \\
\text { (Bo) }\end{array}$} & $\begin{array}{l}\text { (B) LVET } \\
\text { (Bo)(msec) }\end{array}$ & $\begin{array}{l}264.70 \pm 9.59 \\
268.65 \pm 11.45\end{array}$ & .75 & .81 \\
\hline & $\begin{array}{l}\text { (B) SV } \\
\text { (Bo)(mi) }\end{array}$ & $\begin{array}{ll}71.54 \pm & 7.73 \\
74.86 \pm & 8.48\end{array}$ & .95 & .97 \\
\hline
\end{tabular}

Table 4 compares the use of either the zero line or end diastole as the reference level in calculating $\mathrm{dZ} / \mathrm{dt}_{\max }$ and stroke volume. It would appear from the table that the zero line inflates $\mathrm{dZ} / \mathrm{dt}_{\max }$. Since $S V$ is proportional to both LVET and $\mathrm{dZ} / \mathrm{dt}_{\max }$, and both are inflated by the zero crossing method, the zero line method does not seem to be satisfactory for determining SV on a beat by beat basis.

The present study suggests that a fully automated PC-AT signal processing system is feasible and that such a system benefits from algorithms that utilize $Q$ onset to denote the beginning of electrical ventricular systole, the $B$ point of the ICG to denote the aortic opening and end diastole as the reference for determining the amplitude of $\mathrm{dZ} / \mathrm{dt}_{\max }$. The improved precision and reliability introduced by the present system should facilitate the conduct of future validation studies using ICG as a noninvasive tool for studying cardiac output and sympathetic influences upon the myocardium.

Table 4. Variations in Measurement of $\mathrm{dz} / \mathrm{d}_{\mathrm{max}}$

Parameter Mean \pm SE Correlation Reliability $\alpha$ Coefficient $r$

\begin{tabular}{|c|c|c|c|c|c|}
\hline $\begin{array}{l}\mathrm{dZ} / \mathrm{dt}_{\max } \\
\text { from End } \\
\text { Diastole) } \\
\text { (dZe) vs }\end{array}$ & (AZe) & $\begin{array}{l}\mathrm{dZ} / \mathrm{d}_{\mathrm{max}} \\
\text { (ohms/sec) }\end{array}$ & $\begin{array}{l}2.18_{ \pm} 0.17 \\
2.28_{ \pm} 0.17\end{array}$ & .80 & .87 \\
\hline $\begin{array}{l}\mathrm{dZ} / \mathrm{d} \mathrm{t}_{\max } \\
\text { from Zero } \\
\text { Line (dZo) }\end{array}$ & (बZe) & $\begin{array}{l}\text { SV } \\
\text { (ml) }\end{array}$ & $\begin{array}{l}71.22_{ \pm} 6.68 \\
74.82_{ \pm} 7.44\end{array}$ & .88 & .93 \\
\hline
\end{tabular}

\section{ACKNOWLEDGEMENTS}

This research was supported by program project research grant HL36588 and by research training grant HL07426 from the National Heart, Lung and Blood Institute of NIH. 